\section{EMBRYARIDDLE \\ Aeronautical University}

SCHOLARLY COMMONS
International Journal of Aviation, Aeronautics, and Aerospace

\title{
Effects of Exit Doors and Number of Passengers on Airport Evacuation Effeciency Using Agent Based Simulation
}

\author{
Jie Chen \\ chenj5@my.erau.edu \\ Dahai Liu \\ Embry-Riddle Aeronautical University - Daytona Beach, eraufixliu@adoran.box.bepress.com \\ Sirish Namilae \\ Embry-Riddle Aeronautical University, namilaes@erau.edu \\ Sang-A Lee \\ LEES98@my.erau.edu \\ Jennifer E. Thropp \\ Embry-Riddle Aeronautical University - Daytona Beach, throppj@erau.edu \\ Younho Seong \\ yseong@ncat.edu
}

Follow this and additional works at: https://commons.erau.edu/ijaaa

Part of the Aviation Safety and Security Commons, and the Industrial Engineering Commons

\section{Scholarly Commons Citation}

Chen, J., Liu, D., Namilae, S., Lee, S., Thropp, J. E., \& Seong, Y. (2019). Effects of Exit Doors and Number of Passengers on Airport Evacuation Effeciency Using Agent Based Simulation. International Journal of Aviation, Aeronautics, and Aerospace, 6(5). https://doi.org/10.15394/ijaaa.2019.1418

This Article is brought to you for free and open access by the Journals at Scholarly Commons. It has been accepted for inclusion in International Journal of Aviation, Aeronautics, and Aerospace by an authorized administrator of Scholarly Commons. For more information, please contact commons@erau.edu. 


\section{Introduction}

In aviation, evacuation is defined as the urgent abandonment of an aircraft or airport during emergencies, using any available exits. A lot of literature and protocols are readily available, focusing on aircraft evacuation in case of an emergency. However, not a lot of research has been done to identify the evacuation policies at an airport. The Federal Aviation Administration (FAA) provides an advisory circular (AC) to guide airport operators in the development and implementation of an Airport Emergency Plan (AEP). Title 14 Code of Federal Regulations (CFR) part 139.325 requires that certificated airports follow this circular (Federal Aviation Administration, 2017). However, neither the AC nor the CFR defines a specific amount of time for individuals to be evacuated from an airport.

Evacuations at an airport are fundamentally different from any other regular evacuations at malls, buildings, or theaters. Also, airports became an attractive target for terrorists as it allows them to quickly seek international attention (Patankar \& Holscher, 2000). Besides, each airport has different design and layouts, and it is impossible to design a generic evacuation plan that suits all the airports. Evacuation plans that are generally employed to evacuate a building cannot be used for an airport. Therefore, a comprehensive plan to evacuate from an airport should consider the different designs, including their terminals, concourses, and runways.

This study focuses on the current structure of a local airport to investigate how to optimize the evacuation efficiency at emergencies. This study also addressed if these evacuation strategies will be adequate as the number of passengers increases in the future years. Using a simulation software called AnyLogic, we constructed a baseline model. After validating the baseline model, we developed experimental designs, to predict the total evacuation time by changing the passengers' volume and exit paths. AnyLogic is an Agent-Based Model (ABM), which is capable of simulating the evacuation process for airport configurations by altering passenger routes, exit doors, and many other variables.

In this study, the first null hypothesis $\left(\mathrm{H}_{01}\right)$ for the experiment was that an increased number of passengers would not significantly affect the total evacuation time. The second null hypothesis $\left(\mathrm{H}_{02}\right)$ was that the number of exits would not have a significant effect on the total evacuation time.

\section{Statement of the Problem}

Designing evacuation strategies for an airport is sophisticated and incredibly challenging, not to mention the myriad number of different variables that need to be considered. Regular evacuation drills cannot be performed at an airport due to disturbance to normal operations and the costs associated with it. 
Therefore, the next best option is to use computer-based software to simulate the evacuations.

This study considered if an airport can handle evacuations with the increased number of passengers. Research on the airport website revealed the increase in passengers in the coming years. So this future number was also included as one of the levels of the independent variable.

This paper also studied if increasing the number of doors during an evacuation will significantly decrease the evacuation time. We took special consideration to examine the routes of the passengers and if they used doors that were far away from them. Within the simulation, the researcher was able to manipulate the number of doors available.

\section{Literature Review}

Emergency evacuation, a common strategy for handling hazardous situations, is to move individuals from dangerous areas to safer places. Different factors make it more complicated to simulate the situation. In order to understand the factors and to reduce the loss of life in emergency conditions, extensive research has been done to analyze the variables and how it affects evacuation (Cova \& Johnson, 2003; Sheffi et al., 1982; Southworth, 1991; Tuydes \& Ziliaskopoulous, 2004; Wolshon, 2001). Some of the factors are discussed below:

Airports attributes. According to the FAA (2016, p. 1), "The Airports organization provides leadership in planning and developing a safe and efficient national airport system. The office has responsibility for all programs related to airport safety and inspection and standards for airport design, construction, and operation". The FAA (2017) published Part 139 regulation on Safety Management Systems (SMS) to help airports detect and fix safety problems before any accident or incidents happen.

Airport spatial factors. Spatial factors mainly represent building layout information, building configuration, aisle width, and locations of exits. Previous studies showed that evacuees generally evacuate by using familiar routes, which are often the way in where they enter the building (Ashe \& Shields, 1999; Graham \& Roberts, 2000; Kobes et al., 2010). As a result, when selecting evacuation paths in an emergency, familiarity is crucial to the evacuees.

Environmental factors. Environmental factors consist of issues related to spatial factors. For example, variables such as fire, toxic gases, smoke, or hurricane can be considered environmental factors. Previous experiments have demonstrated that these factors significantly reduce the visibility of passengers, making it hard for them to evacuate. In addition, their walking speed also decreases when compared to normal conditions (Gwynne, Galea, Lawrence, \& Filippidis, 2001; Isobe, Helbing, \& Nagatani, 2004). In conclusion, environmental factors should not be ignored when planning and processing the evacuation. 
Human factors. Under extremely high stress during emergent situations, individuals display different characteristics, such as mental stress, fear, or anxiety. In terms of panic behavior, it has been shown that many passengers forget which exit to take and ignore orders from authorities (Ashe \& Shields, 1999; Graham \& Roberts, 2000; Kobes et al., 2010). Helbing, Farkas, and Vicsek (2000) used a mathematical method and computer simulations to simulate panic, stress, and situational awareness to illustrate panic and how it affects crowd dynamics. Additionally, research done by Frank and Dorso (2011) concluded that human factors are a good predictor of group dynamics in emergencies. Overall, these studies showed that human factors are one of the critical factors during evacuation and should be reasonably modeled in any simulation.

Physiological factors. For this study, the physiological factors are the moving speed of evacuees. Galea, Finney, Dixon, Siddiqui, and Cooney (2006) had observed individuals' walking speed and summarized that the average walking speed varies from 1.08 to $1.27 \mathrm{~m} / \mathrm{s}$ in emergency evacuations. Yeo and $\mathrm{He}$ (2009) listed different types of individuals with their walking speed during the evacuation conditions, as shown in Table 1.

Table 1.

Walking Speed According to Influencing Factors

\begin{tabular}{ll}
\hline Occupant type & Speed $(\mathrm{m} / \mathrm{s})$ \\
\hline Children & 1.08 \\
Female elderly & 1.04 \\
Male elderly & 1.05 \\
Elderly & 1.04 \\
Female adult & 1.24 \\
Male adult & 1.30 \\
Adult & 1.27 \\
\hline
\end{tabular}

Note. The walking speeds according to occupant type are average data. All of these data were taken when pedestrian density was less than 0.43 person $/ \mathrm{m}^{2}$. Adapted from "Commuter Characteristics in Mass Rapid Transit in Singapore" by S. K. Yeo and Y. He, 2008, Fire Safety Journal, 44(2), pp. 183-191. Copyright by $\mathrm{S}$ K. Yeo and Y. He.

Decision making. In emergencies, time pressure and uncertainties of the environment, influence evacuees' decision making. The choice of routes is dependent on the complexity of a building layout, availability of the exits, and accessibility of the route (O'Connor, 2005). However, those who work inside the 
airport are more familiar with the internal layout of the airport and can recognize the best escape routes. They can act as emergency leaders during evacuations. Hou, Liu, Pan, and Wang (2014) used a social evacuation model to demonstrate how this 'emergency leadership' could influence an evacuation. Additionally, Dyer et al. (2008) conducted several real-life experiments to test the effectiveness of this 'emergency leadership' on different human groups during evacuations.

AIEva. AIEva is a software that can simulate evacuations when the emergency is due to fire. This system has been widely used for the study of evacuation model in large public buildings in China (Shi, Ren, \& Chen, 2009). The Beijing Municipal Science \& Technology Committee (BMSTC) of China, for example, used this system for the "Project for Crucial Research on Gymnasiums and Stadiums for the 2008 Beijing Olympic Games."

AnyLogic. AnyLogic supports many standard simulation methodologies, such as discrete event modeling and agent-based modeling. Purdue University used this software to assist the Illinois-Indiana-Wisconsin Regional Catastrophic Planning Team in evacuation planning and to build resilience in a major city (Kirby, Dietz, Matson, Pekny, \& Wojtalewicz, 2015).

ARENA. ARENA, developed by Rockwell Automation, has been widely used in various industries for simulation purposes (Kelton, Sawdowski, \& Swets, 2010). It is an event-driven simulation system. Dorton and Liu (2015) have used the software to conduct a simulation model for the study on the effects of baggage volume and alarm rate on an airport security checkpoint.

\section{Methodology}

Figure1 shows the flowchart of the evacuation model at the airport. The simulation clock starts when the first passenger begins to disembark the airport's second floor and ends, immediately, when the last passenger exits through one of the available doors. 


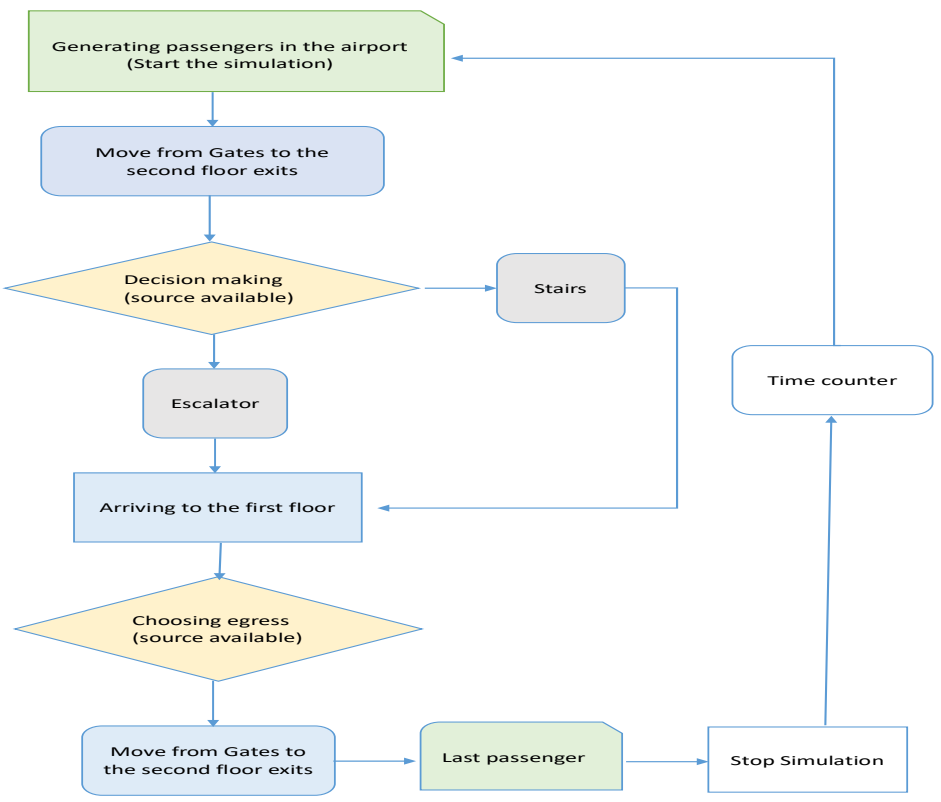

Figure 1. Airport evacuation events flowchart.

\section{Source of Data}

A local airport was chosen as the basic model for this study. This airport has two floors; when the passengers disembark an aircraft, they go through the second floor, then take stairs or elevators to go to the first level. The first level has six exit doors, through which passengers normally exit, as shown in Figure 2. The authors personally observed and collected data, such as passenger arrival rate, passenger traffic volume, etc. Additionally, the authors also calculated that the passengers de-boarding rate was $2.98 \mathrm{sec} /$ person. Additional observations gave the authors the passenger volume per flight and the time for the passengers to exit the airport. 


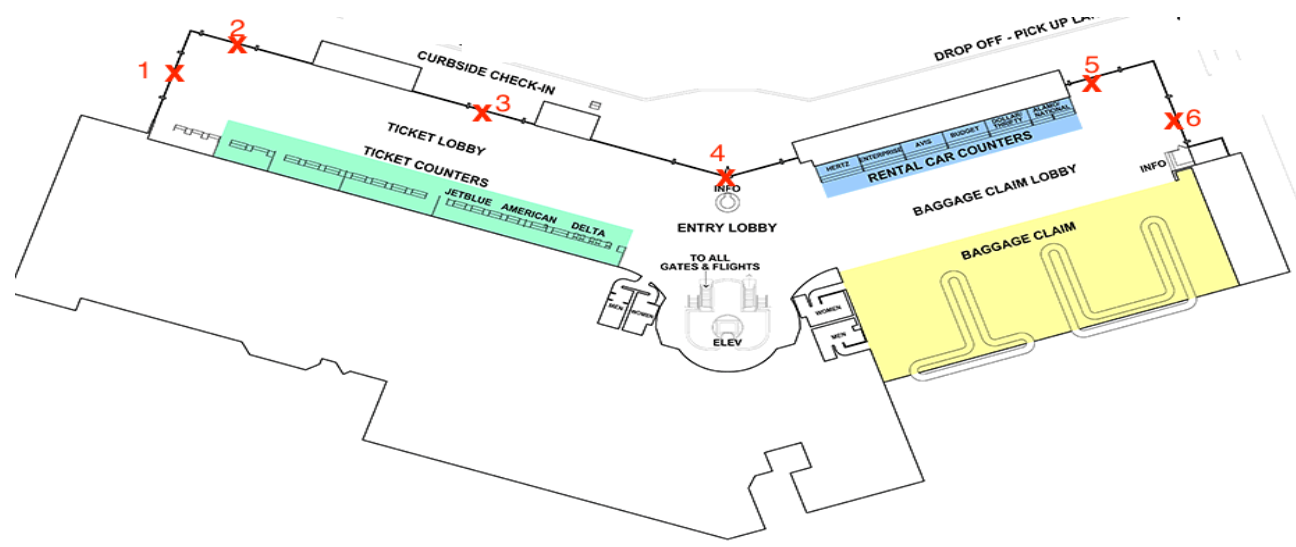

Figure 2. The first floor of the airport.

\section{Independent and Dependent Variables}

The levels of the volumes of the passengers were the first independent variable. There were three levels of the volumes of the passengers. Based on the observations of the researcher at the airport, 111 passengers were leaving the airport when an aircraft arrives. Therefore, this was used in the baseline model. Similarly, the researcher calculated that approximately 600 passengers exit the airport on average in a day. The author used the airport website, for future growth, to conclude that there will be approximately 1000 passengers using the airport in the near future. Based on all this, the levels of the first independent variable was set to 111,600 , and 1000 .

The number of available doors was the second independent variable. The author chose 1, 3, and 5 as the levels of this independent variable. That means, out of the six doors available either 1 , or 3 , or 5 doors were made available for evacuation, and other doors were considered sealed. This helped the author to simulate the evacuation and determine the exit rates based on the doors available. This also helped the researcher to determine if increasing the number of doors will increase the evacuation rate of the passenger. While choosing the doors, some of the doors were intentionally chosen far from the passengers, to see if passengers were prepared to run to doors, that were, far away from them, in case the available doors (that were close to them) were already congested.

The dependent variable is the efficiency of the evacuation, which is measured by the time taken by all the passengers to completely exit the airport. A quantitative approach was used in this study.

\section{Treatment of Data}

AnyLogic was used for simulation while SPSS was used for statistical analysis. AnyLogic was used to change the door exits based on where the 
emergency occurred. The total evacuation time was also obtained from the software. Once the results were obtained, the data was imported into SPSS. Later, the two null hypotheses were tested in SPSS.

A one-way ANOVA was used to test if there was any significant difference in the evacuation times when the levels of volumes of passengers increase. Another one-way ANOVA was run to see if there is a significant difference between evacuation times based on the number of doors available. Later a two-way ANOVA was run to see if there is a significant interaction between the independent variables. Relevant posthoc Sidak tests were conducted, whenever a significance was found in the ANOVA tests. Significance was set to 0.05 for all the tests.

\section{Baseline Model}

For the baseline model, $0.67 \mathrm{~m} / \mathrm{s}$ was considered as the average descending speed on the escalator (Fujiyama \& Tyler, 2010). $1.36 \pm 0.19 \mathrm{~m} / \mathrm{s}$ was used as the average walking speeds based on a study by Chandra and Bharti (2013). The author also used the study done by Boeing (1994) to conclude that the arrival rate of the passengers was $3 \mathrm{sec} /$ person. To maintain safety and prevent chaos, all the passengers were set to the same speed. The baseline model was divided into three steps. It starts with passengers exiting the aircraft on the second floor, choosing either escalator or stairs to reach the first floor and then use one of the exits to leave the airport safely. The real-time observations at the airport by the author was used to compare and validate the baseline model.

\section{Experimental Model}

The experimental model was designed to study the two null hypotheses as already discussed. The first null hypothesis was to check if there is a significant difference in evacuation times based on the levels of volumes of passengers (111, 600 , and 1000). The second null hypothesis was to check if the evacuation times decrease as the number of available doors increase.

\section{Baseline Model Validation Result}

\section{Results}

The baseline model must be validated before any experimentation is done. By observing passengers at the airport, from March 1 to April 13, 2017, the author collected the total time taken by the passengers to leave the airport. It was found that an average of 111 passengers left the airport when an aircraft arrives. This result, along with the different speeds of the passengers, were entered in AnyLogic to create a baseline model. A simulation was run replicating all the parameters discussed above, and the total evacuation time of the passengers was noted. Then a total of 13 simulations were done, and the mean of all the evacuation times was noted. This was then compared to the actual observed evacuation time at the airport through a $t$-test. If no significant difference was found, the baseline is considered validated. 
The null-hypothesis states that there is no significant difference in the evacuation times between the baseline model and the actual observations. An independent t-test concluded was not significant at alpha level of $.05, t(13)=.205$, $\mathrm{p}=.839$. Thus, the baseline model was validated.

\section{Experiment Results}

Number of passengers. A one-way ANOVA indicated that the mean evacuation time for 111 passengers $(M=317.200, S D=18.422)$ was significantly lower than the mean evacuation time for 666 passengers $(\mathrm{M}=516.300, \mathrm{SD}=$ 28.146) and 1000 people $(M=635.917, S D=32.763)$. Sidak Posthoc tests indicated that there was a significant difference between all the levels of passengers. See Tables 2 and 3.

Table 2

Evacuation Times Based on Number of Passengers (in seconds)

\begin{tabular}{|c|c|c|c|c|c|}
\hline \multirow{2}{*}{$\begin{array}{l}\text { Number of } \\
\text { Passengers }\end{array}$} & \multirow{2}{*}{ Mean } & \multirow{2}{*}{$\begin{array}{c}\text { Std. } \\
\text { Deviation }\end{array}$} & \multirow{2}{*}{$\mathrm{N}$} & \multicolumn{2}{|c|}{ 95\% Confidence Interval } \\
\hline & & & & Lower Bound & Upper Bound \\
\hline 111 & 317.200 & 18.422 & 180 & 313.963 & 320.437 \\
\hline 666 & 516.300 & 28.146 & 180 & 513.063 & 519.537 \\
\hline 1000 & 635.917 & 32.763 & 180 & 632.680 & 639.153 \\
\hline
\end{tabular}

Table 3

Sidak Pairwise Comparisons in Evacuation Time (in seconds) - Number of Passengers

\begin{tabular}{cccrr} 
Number of Passengers & Number of Passengers & Mean Difference & Std. Error & Sig. $^{\text {b }}$ \\
\hline 111 & 666 & $-199.100^{*}$ & 2.330 & .000 \\
& 1000 & $-318.717^{*}$ & 2.330 & .000 \\
\hline 666 & 1000 & $-119.617^{*}$ & 2.330 & .000 \\
\hline
\end{tabular}

Note. Based on estimated marginal means

*. The mean difference is significant at alpha level 0.05

Number of exits. A one-way ANOVA indicated the mean for one exit door $(\mathrm{M}=503.156, \mathrm{SD}=153.447)$ was significantly higher than the mean for three exit doors $(\mathrm{M}=483.089, \mathrm{SD}=125.164)$ and five exit doors $(\mathrm{M}=483.172$, $\mathrm{SD}=121.888$ ). Sidak post hoc tests indicated that there was a significant difference between all the numbers of exits. See tables 4 and 5 . 
Table 4

Evacuation Time Based on Number of Available Exits

\begin{tabular}{ccccccc}
\hline \multirow{2}{*}{$\begin{array}{c}\text { Number of } \\
\text { Exits }\end{array}$} & Mean & $\begin{array}{c}\text { Std. } \\
\text { Deviation }\end{array}$ & $\mathrm{N}$ & Lower Bound & Upper Bound \\
\cline { 6 - 7 } & 503.156 & 153.447 & 180 & 499.919 & 506.392 \\
3 & 483.089 & 125.164 & 180 & 479.852 & 486.326 \\
5 & 483.172 & 121.888 & 180 & 479.935 & 486.409 \\
\hline
\end{tabular}

Table 5

Post Hoc Analysis Results - Number of Exits Effects on Evacuation Time (in seconds)

\begin{tabular}{lllll} 
Number of Exits & Number of Exits & Mean Difference & Std. Error & Sig. ${ }^{\mathrm{b}}$ \\
\hline 1 & 3 & $20.067^{*}$ & 2.330 & .000 \\
& 5 & $19.983^{*}$ & 2.330 & .000 \\
\hline 3 & 5 & -.083 & 2.330 & 1.000 \\
\hline
\end{tabular}

Note. Based on estimated marginal means

*. The mean difference is significant at alpha level 0.05

\section{Interaction Between Levels of Passengers and the Number of Exits}

A two-way ANOVA was conducted to see if there was any significant interaction between the levels of passengers and the number of exits. At alpha level 0.05, the ANOVA test indicated that there was a significant interaction between levels of passengers and the exits. A Sidak Posthoc test indicated that the significant interaction exists between all levels of passengers and all the number of exits. The results are shown in Table 6, Table 7, and Figure 3. 
Table 6

Main Effect-Passengers \& Exits (in seconds)

\begin{tabular}{ccccccc}
\hline & & \multicolumn{5}{c}{$95 \%$ Confidence Interval } \\
Passengers & Exits & Mean & SD & Lower Bound & Upper Bound & Sig \\
\hline 111 & 1 & 306.250 & 24.283 & 300.644 & 311.856 & .000 \\
& 3 & 320.367 & 13.012 & 314.760 & 325.973 & .000 \\
& 5 & 324.983 & 8.765 & 319.377 & 330.590 & .000 \\
\hline \multirow{2}{*}{666} & 1 & 535.817 & 39.240 & 530.210 & 541.423 & .000 \\
& 3 & 507.667 & 12.534 & 502.060 & 513.273 & .000 \\
& 5 & 505.417 & 11.089 & 499.810 & 511.023 & .000 \\
\hline 1000 & 1 & 667.400 & 36.873 & 661.794 & 673.006 & .000 \\
& 3 & 621.233 & 15.931 & 615.627 & 626.840 & .000 \\
& 5 & 619.117 & 11.354 & 613.510 & 624.723 & .000 \\
\hline
\end{tabular}

Table 7

Pairwise Comparison - Exits with Different Number of Passengers (in seconds)

\begin{tabular}{cccccc} 
Exits & Passengers & Passengers & Mean Difference & Std. Error & Sig. \\
\hline 1 & 111 & 666 & $-229.567^{*}$ & 4.036 & .000 \\
& & 1000 & $-361.150^{*}$ & 4.036 & .000 \\
\cline { 2 - 6 } & 666 & 111 & $229.567^{*}$ & 4.036 & .000 \\
& & 1000 & $-131.583^{*}$ & 4.036 & .000 \\
\cline { 2 - 6 } & 1000 & 111 & $361.150^{*}$ & 4.036 & .000 \\
& & 666 & $131.583^{*}$ & 4.036 & .000 \\
\hline 3 & 111 & 666 & $-187.300^{*}$ & 4.036 & .000 \\
& & 1000 & $-300.867^{*}$ & 4.036 & .000 \\
& 666 & 111 & $187.300^{*}$ & 4.036 & .000 \\
& & 1000 & $-113.567^{*}$ & 4.036 & .000 \\
\hline 5 & 1000 & 111 & $300.867^{*}$ & 4.036 & .000 \\
& & 666 & $113.567^{*}$ & 4.036 & .000 \\
\hline 5 & 111 & 666 & $-180.433^{*}$ & 4.036 & .000 \\
& & 1000 & $-294.133^{*}$ & 4.036 & .000 \\
\hline & 666 & 111 & $180.433^{*}$ & 4.036 & .000 \\
& & 1000 & $-113.700^{*}$ & 4.036 & .000 \\
\hline & 1000 & 111 & $294.133^{*}$ & 4.036 & .000 \\
& & 666 & $113.700^{*}$ & 4.036 & .000 \\
\hline
\end{tabular}

Note: Based on estimated marginal means

*. The mean difference is significant at alpha level 0.05 . 
b. Adjustment for multiple comparisons: Least Significant Difference (equivalent to no adjustments).

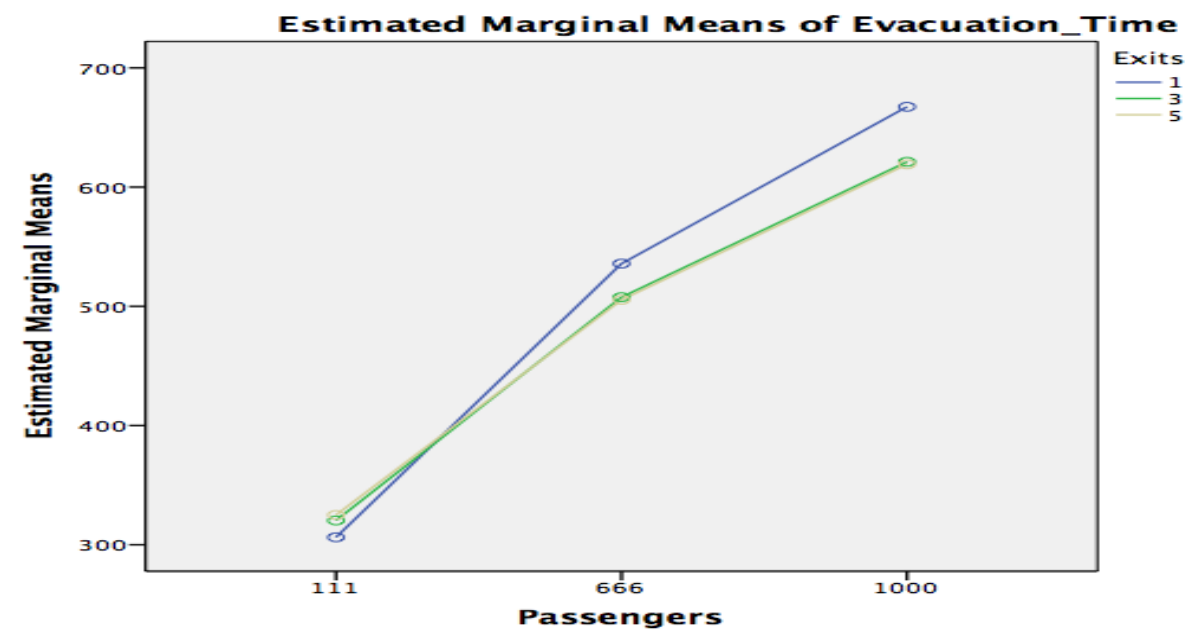

Figure 3. Interaction between the two independent variables.

\section{Discussion}

The statistical tests showed that the passenger volume was the main factor that could influence the total evacuation time. It is natural that as the number of passengers increases the evacuation time also increases. The results of the simulation also showed that the number of exit doors was another main factor that affected the total evacuation time. Interestingly, when there was less number of passengers, and only when only one exit door was available, they spent a significantly lesser time to evacuate than when three and five exit doors were available. However, as the number of passengers increase, the evacuation time decreases as the number of doors increase. These results should not come as a surprise since it can be concluded that as passenger number increases, or the fewer doors available, the congestion time increases.

Significantly, the evacuation time almost remains the same, when only 3 doors and 5 doors were open, and it did not seem to change as the number of levels of passengers increase. This discrepancy may be explained because of the location of door 5. As shown in Figure 2, door 5 is far from passengers, entering the lobby, when compared to doors 1 and 3. So passengers might be trying to evacuate through doors 1 and 3 initially, and only when these doors are congested, used door 5. This discrepancy might be unique to the baseline airport used in the simulation and as such, may not apply to other airports. Since each airport has its own unique layout, each airport should design its exit plan and the number of emergency exits available. 
As shown in Figure 3, and from the statistical results, there was a significant interaction between the independent variable (levels of volumes of passengers and the number of exits). When there were only 111 passengers, there was a significant but weak relationship between the exits. The evacuation time was almost the same. However, the difference becomes significant, and the interference is much more pronounced when the passenger levels increase to 666 and 1000. This is because as the level of passenger increases, and the number of doors to exit decreases evacuation time increases.

Limitations. This study had some limitations. It was assumed that all the passengers walked at a constant velocity. In other words, children, older people, and disabled people were not included in this study. It was also assumed that the passengers did not change their evacuation path dynamically, due to panic. Also, it should be noted that, in case of emergencies, airports use special individual emergency exits for speedy evacuations. These exits were ignored in the study. Due to the unique design of each airport, the same results may not be replicated for different airport designs.

Events during real-life emergencies are incredibly unpredictable. Therefore, the evacuation scenario and the initial conditions will not be exactly similar to the assumptions made for this study. Also, panic and the lack of situational awareness during emergencies, are challenging to simulate in any software, and this should be acknowledged for future research.

\section{Conclusion}

This study produced a valid baseline to simulate passenger's evacuation paths. It also successfully demonstrated that as the number of exits and the levels of passengers has a significant effect on the evacuation times. It also showed that there is a significant interaction between the levels of passengers and the available doors. It was shown that as the number of passengers increase, more doors need to be used for the exit, as it will decrease the amount of time taken by passengers to exit. Other airport administrations can use this method to estimate evacuation time for their airports. The simulation can also be used to see which exits are useful at their airport, based on where the emergency takes place. Therefore, airports can use this study to design better evacuation strategies. Future studies should focus on more realistic and comprehensive evacuation methods. A thorough study needs to be done on people who move at slower speeds, including children and older adults. Other emergency factors such as types of emergencies (e.g., weather, terrorism, hazardous materials), and location of the threat concerning the layout of the facility should also be investigated.

\section{Acknowledgements}

This research was supported by the Center for Advanced Transportation Mobility (CATM), USDOT grant \# 69A3551747125. 


\section{References}

Ashe, B., \& Shields, T. J. (1999). Analysis and modelling of the unannounced evacuation of a large retail store. Fire and Materials, 23(6), 333-336.

Cova, T. J., \& Johnson, J. P. (2003). A network flow model for lane-based evacuation routing. Transportation Research, Part A: Policy Practice, 37A, 579-604.

Dorton, S., \& Liu, D. (2015). Effects of baggage volume and alarm rate on airport security screening checkpoint efficiency using queuing networks and discrete event simulation. Human Factors and Ergonomics in Manufacturing \& Service Industries, 26(1), 95-109.

Dyer, J. R. G., Ioannou, C. C., Morrell, L. J., Croft, D. P., Couzin, I. D., Waters, D. A., \& Krause, J. (2008). Consensus decision making in human crowds. Animal Behaviour, 75(2), 461-470. doi:10.1016/j.anbehav.2007.05.010

Federal Aviation Administration. (2016). Safety management systems (SMS) for airports. Retrieved February 21, 2017, from https://www.faa.gov/airports/ airport_safety/safety_management_systems/

Federal Aviation Administration. (2017). Part 139 airport certification - Airports. Retrieved February 21, 2017, from https://www.faa.gov/airports/ airport_safety/part139_cert/

Frank, G. A., \& Dorso, C. O. (2011). Room evacuation in the presence of an obstacle. Physica A: Statistical Mechanics and its Applications, 390(11), 2135-2145. doi:10.1016/j.physa.2011.01.015

Fujiyama, T., \& Tyler, N. (2010). An explicit study on walking speed of pedestrians on stairs. Transportation Planning and Technology, 33(2), $177-202$.

Galea, E. R., Finney, K. M., Dixon, A. J., Siddiqui, A., \& Cooney, D. P. (2006). Aircraft accident statistics and knowledge database: Analyzing passenger behavior in aviation accidents. Journal of Aircraft, 43(5), 1272-1281.

Graham, T. L., \& Roberts, D. J. (2000). Qualitative overview of some important factors affecting the egress of people in hotel fires. International Journal of Hospitality Management, 19(1), 79-87.

Gwynne, S., Galea, E. R., Lawrence, P. J., \& Filippidis, L. (2001). Modelling occupant interaction with fire conditions using the building EXODUS evacuation model. Fire Safety Journal, 36(4), 327-357. doi:10.1016/s0379-7112(00)00060-6

Helbing, D., Farkas, I. \& Vicsek, T. (2000). Simulating dynamical features of escape panic. Nature, 407, 487-490.

Hou, L., Liu, J.-G., Pan, X., \& Wang, B.-H. (2014). A social force evacuation model with the leadership effect. Physica A: Statistical Mechanics and its Applications, 400, 93-99. doi:10.1016/j.physa.2013.12.049

Isobe, M., Helbing, D., \& Nagatani, T. (2004). Experiment, theory, and 
simulation of the evacuation of a room without visibility. Physical Review E, 69(6), 066132. doi:10.1103/physreve.69.066132

Kelton, D. W., Sawdowski, R. R., \& Swets, N. B. (2010). What is simulation? In D. W. Kelton, R. R. Sawdowski, \& N. B. Swets, Simulation with arena (5th ed., p. 10). New York, NY: McGraw-Hill Companies, Inc.

Kirby, A. M., Dietz, J. E., Matson, E. T., Pekny, J. F., \& Wojtalewicz, C. (2015). Major city evacuation planning using simulation modeling. International Journal of Disaster Resilience in the Built Environment, 6(4), 397-408. doi:10.1108/ijdrbe-07-2014-0058

Kobes, M., Helsloot, I., de Vries, B., Post, J. G., Oberijé, N., \& Groenewegen, K. (2010). Way finding during fire evacuation; an analysis of unannounced fire drills in a hotel at night. Building and Environment, 45(3), 537-548.

O Connor, D. J. (2005). Integrating human behavior factors into design an examination of behaviors that increase or reduce harm from fires. Fire Protection Engineering, 28, 8.

Patankar, M. S., \& Holscher, L. (2000). Accessibility vs security: The challenge to airport security systems. Security Journal, 13(2), 7-19.

Sheffi, Y., Mahmassani, H. S., \& Powell, W. B., (1982). A transportation network evacuation model. Transportation Research, Part A, 16A 3, 209-218.

Shi, J., Ren, A., \& Chen, C. (2009). Agent-based evacuation model of large public buildings under fire conditions. Automation in Construction, 18(3), 338347. doi:10.1016/j.autcon.2008.09.009

Southworth, F. (1991). Regional evacuation modeling: A state-of-the-art review. ORNL/TM-11740. Oak Ridge, TN: Oak Ridge National Labs.

Tuydes, H., \& Ziliaskopoulos, A. (2004). Network redesign to optimize evacuation contraflow. Proceedings of the 83rd Annual Meeting, Washington, D.C.: Transportation Research Board.

Wolshon, B. (2001). One-way-out: Contra flow freeway operation for hurricane evacuation. National Hazards Review, 23, 105-112.

Yeo, S. K., \& He, Y. (2009). Commuter characteristics in mass rapid transit stations in Singapore. Fire Safety Journal, 44(2), 183-191. 